\title{
A semi-analytical solution to organic contaminants transport through composite liners considering a single crack in CCL
}

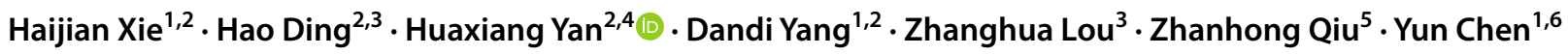

Received: 5 October 2021 / Accepted: 14 December 2021 / Published online: 27 January 2022

(c) The Author(s) 2022

\begin{abstract}
Compacted clay liners (CCLs) are extensively used as engineering barriers for groundwater and soil pollution. The existence of cracks/fractures in CCL caused by thermally induced shrinkage is reported to importantly damage the performance of the CCL. An analytical model is developed to study the effects of the cracks/fractures on the migration of organic contaminants through a composite liner system. Laplace transformation and Laplace inversion using the Stehfest method are adopted to derive the analytical solution, which is validated by the experimental data. The existence of crack shows a significant impact on the breakthrough curve and bottom flux of organic contaminants. Increasing the crack width from 1 to $25 \mathrm{~mm}$ results in an enhancement of contaminant bottom concentration by a factor of 280. Increasing the adsorption factor and degradation rate of contaminants can effectively improve the performance of the composite liner with cracks. The effects of degradation of contaminants on the breakthrough curve are found to be more significant for the case with a larger retardation factor. This may be due to the fact that increasing the retardation factor can significantly slow down the transport of contaminants, which may indirectly create a longer period for the degradation of contaminants.
\end{abstract}

Keywords Landfill composite liner $\cdot$ Organic contaminant $\cdot$ Cracks $\cdot$ Semi-analytical solution

Responsible Editor: Marcus Schulz

Huaxiang Yan

huaxiang.yan@manchester.ac.uk

1 Center for Balance Architecture, Zhejiang University, 148 Tianmushan Rd., Hangzhou 310007, China

2 College of Civil Engineering and Architecture, Zhejiang University, 866 Yuhangtang Rd., Hangzhou 310058, China

3 Ocean College, Zhejiang University, Zheda Rd., Zhoushan 316021, China

4 Department of Mechanical, Aerospace and Civil Engineering, School of Engineering, The University of Manchester, Manchester M13 9PL, UK

5 School of Civil Engineering and Architecture, Taizhou University, Taizhou 318000, China

6 The Architectural Design and Research Institute of Zhejiang University Co. Ltd., 148 Tianmushan Rd., Hangzhou 310058, China

\section{Introduction}

Landfilling is currently one of the main methods of disposal of municipal waste. The sanitary volume of municipal domestic waste in mainland China was reported to be 109.480 million tons with a landfill disposal rate of $45.23 \%$ (NBSC 2019). Even at regular landfills, leachate with complex components can still form during long-term operation and pose a threat to the environment. There were 1259 organic compounds detected from rivers and wells around the landfill reported by the U.S. Environmental Protection Agency (USEPA) in 1976 (Shackelford and Keith 1976; Kjeldsen et al. 2002). Öman and Junestedt 2008) screened leachate samples from 12 Swedish municipal landfill sites for 400 parameters and compounds where more than 90 organic and metal-organic compounds were detected. Masoner et al. (2014) sampled fresh leachate from 19 landfills across the USA during 2011. A total of 129 out of 202 contaminants of emerging concern (CECs) were detected, including 62 prescription pharmaceuticals, 23 industrial chemicals, 18 nonprescription pharmaceuticals, 16 household chemicals, 6 steroid hormones, and 4 plant/animal sterols. Most of them are organic contaminants. 
It is important to study organic contaminant transport as they can cause very serious harm to humans and various organisms in nature, including serious ecological hazards and risks (Batt et al. 2017; Peng et al. 2018; Koual et al. 2019; Espinosa-Reyes et al. 2019). For example, polychlorinated biphenyl (PCB) can lead to neurological, endocrine, genetic, and systemic adverse effects in the human body (Hens and Hens 2018). Polycyclic aromatic hydrocarbons (PAHs) are associated with risks to human health (e.g., carcinogenesis) (Sampaio et al. 2021). Some phenolic compounds are known to be endocrine-disrupting compounds (EDCs), which have a detrimental effect on the endocrine system, such as 2,4,6-trichlorophenol (2,4,6-TCP) (Chen et al. 2021).

Predictive capability for a quantitative assessment of the contaminant transport processes is necessary for designing an effective and well-operational liner system. Although numerical models are generally used to study the contaminant transport problems, some complex numerical simulations are very time-consuming due to the large amount of data required to support the numerical models. Analytical solutions are therefore critically important for understanding many scientific phenomena (e.g., contaminant transport, heat transfer, and deformation), even though simplifications may be made to derive them (Yan et al. 2021c). Especially, analytical solutions play a unique role in verifying many new numerical methods. For example, the simplified analytical solutions, however, allow assessment of the sensitivity to various instabilities involved in the transport of contaminants in various landfill barrier systems and verification of the results of complex analyses (Rowe et al. 2004; Dejam 2019; Feng et al. 2020). For these reasons, analytical solutions have been extensively derived in recent years for investigating the performance of composite liner under different conditions (Xie et al. 2013, 2015a, b, 2016; Rowe and Abdelatty 2013; Wu et al. 2017; Feng et al. 2019; Yan et al. $2021 \mathrm{a}, \mathrm{b})$. The existing analytical models mentioned above were developed based on the assumption of intact clay liner without fractures/cracks. However, the cracks can be easily induced in the liner system, such as shrinkage cracks due to tension generated during drying (Inci 2008; Tang et al. 2008b), thermal cracks due to thermal stress changes in the soil material (Tang et al. 2008a), tensile cracks due to overburden pressure changes (Wu et al. 2012), and fracture cracks due to fracture loads such as external loads and internal cyclic loads (Pal et al. 2009; Wei et al. 2020).

Numerous studies and experimental observations have shown that the formation of cracks in the clay barrier provides a preferential flow for contaminants (Omidi et al. 1996; Rayhani et al. 2007; Li et al. 2016, 2018). The cracks reported from the field observations can reach $15-30 \mathrm{~mm}$ in width and $2 \mathrm{~m}$ in depth (Ritchie and Adams 1974; Basnett and Brungard 1992; Omidi et al. 1996). The mechanisms for clay desiccation processes have been mainly investigated by using numerical approaches, including the finite element method (FEM) (Trabelsi et al. 2012; Hirobe and Oguni 2017) and the discrete element method (DEM) (Sima et al. 2014; Wei et al. 2020). Studies have also focused on developing analytical models for investigating solute transport in porous media with cracks. An analytical model of solute transport through a single fracture was first proposed by Tang et al. (1981). The model was then extended by Roubinet et al. (2012) to investigate the influences of transverse dispersion in the fracture and longitudinal diffusion in the matrix on solute transport. Other modelling efforts have focused on reactive transport (Zhu et al. 2016), advective-dominated systems (Birkhölzer et al. 1993; Odling and Roden 1997; Houseworth et al. 2013), fracture networks (Cvetkovic and Frampton 2012; Haddad et al. 2012). The above studies were designed for investigating the contaminant transport through fractured rock and other environmental groundwater contaminant problems (e.g., nuclear waste disposal and contaminant removal from the fractured rocks) (Zhu et al. 2016). However, the composite liners of landfills generally consist of CCL and geomembrane (GMB), which is placed on the CCL to inhibit the transport through advection. Additionally, the cracks in the clay liner can create pathways for contaminant transport, which will decrease the performance of clay barriers used for waste isolation (Wan et al. 2018; DeCarlo and Shokri 2014). The traditional diffusion model (e.g., Xie et al. 2013; Rowe and Abdelatty 2013; Wu et al. 2017; Feng et al. 2019; Yan et al. 2021a, b) may lead to overestimation of the performance of composite liner with cracked clay.

The aim of this article is to address the issue in relation to the extent of the effects of cracks in the clay liner on the overall transport of contaminants in a composite liner system by developing a new analytical solution. The developed analytical model can be used to investigate the breakthrough of the organic contaminant through composite liners with cracks or design a more conservative barrier system. The effects of degradation of organic contaminants, the porosity of the CCL, crack width, and the partition coefficient of organic contaminants in GMB are investigated. Additionally, the present analytical solution may be an extension for investigating nuclear waste storage facilities, groundwater pollution problems, and shale gas extraction in a fractured system.

The paper is organised as follows. The next section presents the mathematical model development and basic assumptions for contaminant migration in composite liners with cracks. The third section shows the analytical solution to the problem, while the fourth section presents the validation of the proposed analytical solution against a set of experimental data. Results and discussions presents the results of parametric studies of the effects of several key factors (e.g., crack width, degradation and adsorption of 


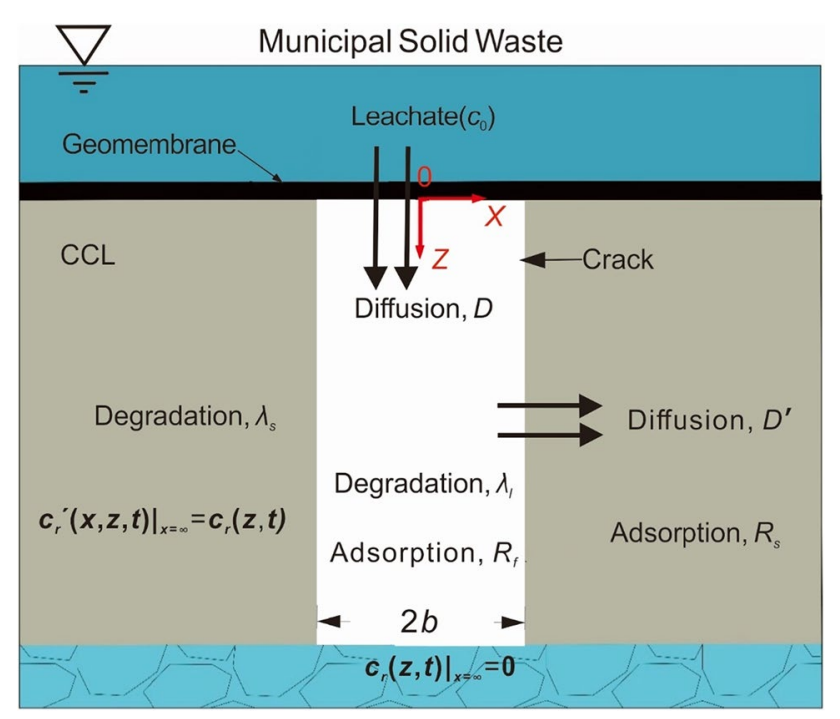

Fig. 1 The conceptual model of contaminant transport through a cracked composite liner system

contaminants, and porosity of clay) on the overall transport behaviour of contaminants. Conclusions from the work are given in the last section.

\section{Mathematical model}

In this study, we consider a composite liner consisting of intact GMB and CCL with a regular strip crack of $2 b$ width and infinite depth in the CCL. It should be noted that using an infinite depth of composite liner may result in conservative predictions of contaminant transport (Foose 2002) and facilitate the development of analytical models. The GMB is placed on the CCL. The source of leachate contaminant is assumed to be constant. The organic contaminant in the leachate may transport through the GMB by diffusion and then enter the crack. The contaminant transport mechanisms in CCL include diffusion, adsorption on solid particles, and degradation of organic contaminants. The origin of the coordinate axis is the opening of the crack, and the $z$-axis is positive downward (as shown in Fig. 1).

The basic assumptions of the present model are as follows: (i) the width of the crack is much smaller than its length; and therefore, the width is negligible with respect to the length. (ii) In the crack, the contaminants are fully diffused and dispersed in the lateral direction, and complete mixing in the lateral direction is maintained throughout the flow process; (iii) the CCL is isotropic and homogeneous; (iv) the transport of contaminants along the crack direction is much faster than that in the matrix of CCL; and (v) adsorption is a linear and equilibrium process.

\section{Governing equation of organic contaminant transport}

By using the total balance of contaminants in the crack, we are able to establish the following governing equation (Tang et al. 1981; Xie et al. 2019):

$\frac{\partial c_{r}(z, t)}{\partial t}+\frac{1}{b} \frac{\partial s}{\partial t}=D \frac{\partial^{2} c_{r}(z, t)}{\partial z^{2}}-\lambda_{l}\left[c_{r}(z, t)-\frac{s}{b}\right]-\frac{q}{b} 0 \leq z \leq \infty$

and

$\lambda_{l}=(\ln 2) / t_{f, 1 / 2}$

where $z$ is a coordinate along the crack axis, $\mathrm{L}$; $t$ is time, T; $c_{r}(z, t)$ is the concentration of contaminants in cracks, $\mathrm{M} / \mathrm{L}^{3}$; $s$ is the mass of pollutants absorbed on CCL per unit length of crack surface, $\mathrm{M} / \mathrm{L}^{2} ; b$ is half the width of the crack, $\mathrm{L}$; $\lambda_{l}$ is first-order degradation rate coefficient of organic contaminants, $1 / \mathrm{T} ; t_{f, 1 / 2}$ is the half-life of organic contaminants in cracks, $\mathrm{T} ; q$ is diffusive flux perpendicular to the crack axis, $\mathrm{M} / \mathrm{L}^{2} \mathrm{~T} ; D$ is the diffusion coefficient of organic contaminants in cracks, $\mathrm{L}^{2} / \mathrm{T}$.

Assuming that the absorption process of contaminants at the crack surface obeys linear equilibrium, the dissolution and absorption processes can be expressed by the following two equations (Tang et al. 1981):

$s=\frac{d s}{d c} c_{r}(z, t)=\kappa_{f} c_{r}(z, t)$

$\frac{\partial s}{\partial t}=\frac{\partial s}{\partial c_{r}(z, t)} \frac{\partial c_{r}(z, t)}{\partial t}=\kappa_{f} \frac{\partial c_{r}(z, t)}{\partial t}$

where $\kappa_{f}$ is the distribution coefficient.

By substituting Eqs. (3a) and (3b) into Eq. (1), the governing equation describing the transport of organic contaminants in the crack is transformed into (Tang et al. 1981)

$R_{f} \frac{\partial c_{r}(z, t)}{\partial t}=D \frac{\partial^{2} c_{r}(z, t)}{\partial z^{2}}-\lambda_{l} R_{f} c_{r}(z, t)-\frac{q}{b} 0 \leq z \leq \infty$

and

$R_{f}=1+\frac{\kappa_{f}}{b}$

where $R_{f}$ is the crack retardation factor.

Similarly, the transport of contaminants in CCL can be obtained by considering the total balance of contaminants per unit width and the diffusion perpendicular to the crack direction (Tang et al. 1981; Xie et al. 2019):

$\frac{\partial c_{r}^{\prime}(x, z, t)}{\partial t}+\frac{\rho_{b}}{\theta} \frac{\partial s^{\prime}}{\partial t}=D^{\prime} \frac{\partial^{2} c_{r}^{\prime}(x, z, t)}{\partial x^{2}}-\lambda_{s}\left(c_{r}^{\prime}(x, z, t)+\frac{\rho_{b}}{\theta} s^{\prime}\right) b \leq x \leq \infty$

and 
$\lambda_{s}=(\ln 2) / t_{s, 1 / 2}$

where $x$ is the coordinate perpendicular to the crack axis, $\mathrm{L} ; c_{r}^{\prime}(x, z, t)$ is the concentration of contaminants in solution, $\mathrm{M} / \mathrm{L}^{3} ; s^{\prime}$ is the mass of solute absorbed per unit of solid in $\mathrm{CCL}, \mathrm{M} / \mathrm{L}^{2} ; \rho_{b}$ is the density of CCL, $\mathrm{M} / \mathrm{L}^{3} ; \theta$ is the porosity of CCL; $\lambda_{s}$ is the first-order degradation rate coefficient of organic contaminants in CCL, $1 / \mathrm{T}$; and $t_{s, 1 / 2}$ is the half-life of organic contaminants in the matrix of CCL, T.

In the above equation, the effective diffusion coefficient $D^{\prime}$ is defined as

$D^{\prime}=\tau D$

where $\tau$ is the matrix tortuosity (Bear 2013).

A linear equilibrium isotherm adsorption model is used to describe the sorption of contaminant on CCL as follows:

$s^{\prime}=\frac{d s^{\prime}}{d c_{r}^{\prime}(x, z, t)} c_{r}^{\prime}(x, z, t)=\kappa_{m} c_{r}^{\prime}(x, z, t)$

$\frac{\partial s^{\prime}}{\partial t}=\frac{d s^{\prime}}{d c_{r}^{\prime}(x, z, t)} \frac{\partial c_{r}^{\prime}(x, z, t)}{\partial t}=\kappa_{m} \frac{\partial c_{r}^{\prime}(x, z, t)}{\partial t}$

where $\kappa_{m}$ is the distribution coefficient in CCL. The CCL retardation factor can be defined as

$R_{s}=1+\frac{\rho_{b}}{\theta} \kappa_{m}$

Combining Eqs. (6), (9), and (10), the governing equation of CCL can be obtained:

$\frac{\partial c_{r}^{\prime}(x, z, t)}{\partial t}-\frac{D^{\prime}}{R_{s}} \frac{\partial^{2} c_{r}^{\prime}(x, z, t)}{\partial x^{2}}+\lambda_{s} c_{r}^{\prime}(x, z, t)=0 b \leq x \leq \infty$

At this point, let us consider the loss term due to diffusion in Eq. (5). This loss term represents the diffusion flux through the cracked-CCL interface. This flux can be expressed according to Fick's first law as

$q=-\left.\theta D^{\prime} \frac{\partial c_{r}^{\prime}(x, z, t)}{\partial x}\right|_{x=b}$

Substituting Eq. (12) into Eq. (5) results in the contaminant migration in the crack:

$\frac{\partial c_{r}(z, t)}{\partial t}-\frac{D}{R_{f}} \frac{\partial^{2} c_{r}(z, t)}{\partial z^{2}}+\lambda_{l} c_{r}(z, t)-\left.\frac{\theta D^{\prime}}{b R_{s}} \frac{\partial c_{r}^{\prime}(x, z, t)}{\partial x}\right|_{x=b}=00 \leq z \leq \infty$

\section{Boundary and initial conditions}

The concentration of contaminants inside the GMB can be described by the following equation (El-Zein 2008; Xie et al. 2013):
$D_{g} \frac{d^{2} c_{g}(z)}{d z^{2}}=0\left(-L_{g} \leq z \leq 0\right)$

where $c_{\mathrm{g}}(\mathrm{z})$ is the concentration of organic contaminants in $\mathrm{GMB}, \mathrm{M} / \mathrm{L}^{3} ; D_{g}$ is the effective diffusion coefficient of organic contaminants in $\mathrm{GMB}, \mathrm{L}^{2} / \mathrm{T}$; and $\mathrm{L}_{\mathrm{g}}$ is the thickness of GMB, L.

Assuming that the concentration of organic contaminants in the leachate on the GMB is a constant (e.g., $\mathrm{c}_{0}=1 \mathrm{mg} / \mathrm{L}$ ). A constant contaminant concentration assumption at the top of the GMB is a relatively reasonable boundary condition, which is a relatively conservative estimate of the contaminant transport (Shackelford 1990; Foose 2002). The top boundary condition can be described using the following equation (Rowe 2005):

$c_{g}\left(-L_{g}\right)=c_{0} S_{g f}$

where $S_{\mathrm{gf}}$ is partition coefficients between leachate and GMB.

The continuity of contaminant fluxes and concentrations must be satisfied at the interface between the GMB and the CCL. The continuity of the contaminant flux can be described by Fick's first law (Foose 2002)

$\left.D_{g} \frac{d c_{g}(z)}{d z}\right|_{z=0}=\left.\theta D^{\prime} f_{r}(z, t)\right|_{z=0}$

where $f_{r}(z, t)$ can be expressed by the following equation:

$f_{r}(z, t)=\frac{\partial c_{r}(z, t)}{\partial z}$

Assuming that the contaminants passing through the GMB will enter the crack completely, there should be a continuity of flow and concentration at the interface between the crack and the GMB, and the continuity of concentration at the interface of the GMB and the CCL can be expressed by the following equation (Kalbe et al. 2002; Chen et al. 2009)

$\frac{c_{g}(0)}{S_{g f}^{\prime}}=c_{r}(0, t)$

where $S^{\prime}{ }_{\text {gf }}$ is the partition coefficient of contaminants between GMB and fluid outside the GMB (Sangam and Rowe 2001); at present, there are relatively few studies on the value of $S^{\prime}{ }_{\text {gf }}$, which is usually considered to be equal to $\mathrm{S}_{\mathrm{gf}}($ Xie et al. 2013).

The solution to Eq. (14) satisfying the boundary conditions Eqs. (15), (16), and (18) can be expressed as (Hahn and Özisik 2012)

$c_{g}(z)=\alpha_{1}+\beta_{1} z$ 
where $\alpha_{1}$ and $\beta_{1}$ are the constants to be solved based on the boundary conditions. Substituting the above equation into Eqs. (15) and (18), we are able to obtain $\alpha_{1}$ and $\beta_{1}$ as follows:

$\alpha_{1}=c_{r}(0, t) S_{g f}^{\prime}$

$\beta_{1}=\frac{c_{r}(0, t) S_{g f}^{\prime}-c_{0} S_{g f}}{L_{g}}$

Substituting Eq. (19) into Eq. (16), we can obtain the functional relationship between $f_{r}$ and $c_{r}$

$c_{r}(0, t)=\eta_{1}+\eta_{2} f_{r}(0, t)$

and

$\eta_{1}=\frac{c_{0} S_{g f}}{S_{g f}^{\prime}}$

$\eta_{2}=\frac{\theta D^{\prime} L_{g}}{D_{g} S^{\prime}{ }_{g f}}$

In summary, the boundary conditions for contaminant transport in cracks (Eq. 13) can be written as

$c_{r}(0, t)=\eta_{1}+\left.\eta_{2} \frac{\partial c_{r}(z, t)}{\partial z}\right|_{z=0}$

$c_{r}(\infty, t)=0$

$c_{r}(z, 0)=0$

Similarly, boundary conditions for contaminant transport in CCL (Eq. 11) are

$c_{r}^{\prime}(b, z, t)=c_{r}(z, t)$

$c_{r}^{\prime}(\infty, z, t)=0$

$c_{r}^{\prime}(x, z, 0)=0$

\section{Analytical solutions}

\section{Steady-state solution}

In the steady state, Eq. (13) describing the contaminant transport process in the crack can be simplified to the following equation:

$$
-\frac{D}{R_{f}} \frac{\partial^{2} c_{r}(z)}{\partial z^{2}}+\lambda_{l} c_{r}(z)-\left.\frac{\theta D^{\prime}}{b R_{f}} \frac{\partial c_{r}^{\prime}(x, z)}{\partial x}\right|_{x=b}=00 \leq z \leq \infty
$$

The boundary conditions are

$c_{r}(0)=\eta_{1}+\left.\eta_{2} \frac{\partial c_{r}(z)}{\partial z}\right|_{z=0}$

$c_{r}(\infty)=0$

Equation (11) can be simplified to the following equation:

$-\frac{D^{\prime}}{R_{s}} \frac{\partial^{2} c_{r}^{\prime}(x, z)}{\partial x^{2}}+\lambda_{s} c_{r}^{\prime}(x, z)=0 b \leq x \leq \infty$

The boundary conditions are

$c_{r}^{\prime}(b, z)=c_{r}(z)$

$c_{r}^{\prime}(\infty, z)=0$

Equation (25) is a typical partial differential equation, and its solution should have the following form:

$c_{r}^{\prime}=\alpha_{2} e^{-B \lambda_{s}^{1 / 2}(x-b)}+\beta_{2} e^{+B \lambda_{s}^{1 / 2}(x-b)}$

and

$B=\left(\frac{R_{s}}{D^{\prime}}\right)^{1 / 2}$

The value of $\alpha_{2}$ and $\beta_{2}$ can be obtained by substituting the solution Eq. (27) into the boundary conditions Eq. (26) leading to

$c_{r}^{\prime}(x, z)=c_{r}(z) e^{-B \lambda_{s}^{1 / 2}(x-b)}$

Substituting Eq. (29) into Eq. (23) and satisfying the boundary conditions required by Eq. (24); the transport solution equation of the contaminant in the crack can be obtained as

$c_{r}(z)=\frac{\eta_{1}}{1-g \eta_{2}} e^{g z}$

and

$g=-\left[\frac{\left(\lambda_{l} R_{f} b+\theta D^{\prime} B \lambda_{s}{ }^{1 / 2}\right)}{b D}\right]^{1 / 2}$ 


\section{Transient solution}

For the coupled system consisting of Eqs. (11), (13), (21), and (22), the transient solution method will be shown below.

The Laplace transform of Eq. (11)

$p \bar{c}_{r}^{\prime}=\frac{D^{\prime}}{R_{s}} \frac{d^{2} \bar{c}_{r}^{\prime}}{d x^{2}}-\lambda_{s} \bar{c}_{r}^{\prime}$

where $\bar{c}_{\mathrm{r}}^{\prime}$ is the Laplace deformation of $\mathrm{c}_{\mathrm{r}}^{\prime}$.

$\bar{c}_{r}^{\prime}(x, z, p)=\int_{0}^{\infty} \exp (-p t) c_{r}^{\prime}(x, z, p) d t$

The solution is similar to Eq. (29), and the unique solution satisfying the boundary conditions takes the form

$\bar{c}_{r}^{\prime}=c_{1}^{\prime} e^{-B P_{s}^{1 / 2}(x-b)}$

$P_{s}=p+\lambda_{s}$

In this equation, the constant $\mathrm{c}_{1}^{\prime}$ can be obtained using Eq. (22a) and after substituting into Eq. (34)

$\bar{c}_{r}^{\prime}=\bar{c}_{r} e^{-B P_{s}^{1 / 2}(x-b)}$

The derivative of $\bar{c}_{\mathrm{r}}^{\prime}$ at the intersection $x=b$ is

$\left.\frac{d \bar{c}_{r}^{\prime}}{d x}\right|_{x=b}=-B P_{s}^{1 / 2} \bar{c}_{r}$

Applying the Laplace transform to Eq. (13), we can obtain

$p \bar{c}_{r}+\lambda_{l} \bar{c}_{r}=\left.\frac{\theta D^{\prime}}{b R_{f}} \frac{d \bar{c}_{r}^{\prime}}{d x}\right|_{x=b}+\frac{D}{R_{f}} \frac{d^{2} \bar{c}_{r}}{d z^{2}}$

Substituting Eq. (37) into Eq. (38)

$\frac{d^{2} \bar{c}_{r}}{d z^{2}}-\frac{R_{f}}{D}\left(P_{l}+\frac{P_{s}^{1 / 2}}{A}\right) \bar{c}_{r}=0$

and

$A=\frac{b R_{f}}{\theta\left(R_{s} D^{\prime}\right)^{1 / 2}}$

$P_{l}=p+\lambda_{l}$

Equation (39) is a second-order ordinary differential equation, which has the general solution in the form

$\bar{c}_{r}=c_{2} e^{z r_{+}}+c_{3} e^{z r_{-}}$

where $\mathrm{c}_{2}$ and $\mathrm{c}_{3}$ are undetermined constants, and $r$ has two forms $r_{ \pm}= \pm\left[R_{f}\left(\frac{P_{s}{ }^{1 / 2}}{A}+P_{l}\right) / D\right]^{1 / 2}$

Since the solution value is finite, the first term in Eq. (42) must be eliminated, which means that $c_{2}$ must be equal to 0 . We get the remaining term, and Eq. (42) is transformed into

$\bar{c}_{r}=c_{3} e^{-z\left[R_{f}\left(\frac{P_{s}^{1 / 2}}{A}+P_{l}\right) / D\right]^{1 / 2}}$

Using Eq. (21a), we are able to obtain $c_{3}$ in the above equation. Applying the Laplace transform to Eq. (21a),

$\bar{c}_{r}(0, p)=\frac{\eta_{1}}{p}+\left.\eta_{2} \frac{\partial \bar{c}_{r}(z, p)}{\partial z}\right|_{z=0}$

Substituting Eq. (44) into Eq. (45)

$\bar{c}_{r}(p)=\frac{\eta_{1}}{p\left(1+\eta_{2} \xi\right)} e^{-z \xi}$

and

$\xi=\left[R_{f}\left(\frac{P_{s}^{1 / 2}}{A}+P_{l}\right) / D\right]^{1 / 2}$

Using Stehfest's numerical inversion method (Stehfest 1970a, b) for the Laplace inversion variation, we are able to obtain a semi-analytical solution of this equation

$c_{r}(t)=\frac{\ln 2}{t} \sum_{i=1}^{N} V_{i} \bar{c}_{r}(p)$

and

$p=\frac{i \ln 2}{t}$

$V_{i}=(-1)^{\frac{N}{2}+i} \times \sum_{k=\left[\frac{i+1}{2}\right]}^{\min \left(i, \frac{N}{2}\right)} \frac{k^{\frac{N}{2}}(2 k) !}{\left(\frac{N}{2}-k\right) ! k !(k-1) !(i-k) !(2 k-i) !}$

where $N$ is an even number. A better range of the values of $N$ is from 10 to 14 (Lee et al. 1984). In this paper, $N$ is taken as 10. Using Stehfest's numerical inversion method, a semianalytical solution of the concentration equation in the crack and CCL can be obtained.

The contaminant flux at any time in the crack at $z=L$ can be obtained by the following equation:

$J(L, t)=-\left.n D \frac{\partial \bar{c}_{r}(z, t)}{\partial z}\right|_{z=L}$ 


\section{Validation of the proposed analytical solution}

Experimental results from solute transport in CCL with a crack test was used to validate the proposed solution. The experiments carried out by Li et al. (2018) investigated the effect of cracks in CCL on the solute transport through the liner. The height of the soil column was $0.25 \mathrm{~m}$. The concentration of contaminant (e.g., $\mathrm{Cl}^{-}$) at the top of CCL was fixed at $10,000 \mathrm{mg} / \mathrm{L}$. The diffusion coefficient of $\mathrm{Cl}^{-}$in CCL was reported to be $8.93 \times 10^{-10} \mathrm{~m}^{2} / \mathrm{s}$. Figures $2 \mathrm{a}$ and $\mathrm{b}$ show the spatial concentration of $\mathrm{Cl}^{-}$under different crack thickness at $30 \mathrm{~d}, 40 \mathrm{~d}$, and $50 \mathrm{~d}$. The data reproduced from the literature is obtained by using the function of Digitizer in Origin Pro 2016. A good match between the analytical solution and experimental data can be found in Fig. 2. In this section, the coefficient of determination $\left(R^{2}\right)$ is used to show the validity of the present model. The $R^{2}$ is given as

$R^{2}=1-\frac{\sum_{i=1}^{n}\left(y_{i}-\hat{y}_{i}\right)^{2}}{\sum_{i=1}^{n}\left(y_{i}-\bar{y}\right)^{2}}$

where $n$ is the number of measurements, $y_{i}$ is the value of the $i$ th observation in the experimental dataset, $\hat{y}_{i}$ is the predicted value for the $i$ th observation, and $\bar{y}$ is the average value of the validation dataset.

The $R^{2}$ for the case with different crack widths and times is shown in Table 1. Generally, the present model shows a good prediction ability for the transport of contaminants in CCL. Additionally, the proposed analytical model shows a better performance for the case with larger crack width (see Table 1). It can be seen that the crack in CCL may significantly shorten the breakthrough of organic contaminants. For example, the maximum diffusion depth of contaminant (e.g., $\mathrm{Cl}^{-}$) is around $0.04 \mathrm{~m}$ in CCL without cracks at 50 days (Yan et al. 2021c). However, the concentration reaches $25 \mathrm{mg} / \mathrm{L}$ at the bottom of CCL for $b=7.5 \mathrm{~mm}$ at 50 days (Fig. 2a). The above results highlight the potential unpleasant breakthrough of contaminants in the liner barrier with the existence of cracks in the CCL.

\section{Results and discussions}

Benzene was chosen to represent the contaminants in the landfill leachate. The thicknesses of the GMB and CCL are $1.5 \mathrm{~mm}$ and $0.75 \mathrm{~m}$, respectively. The parameters used in this section are summarized in Table 2.

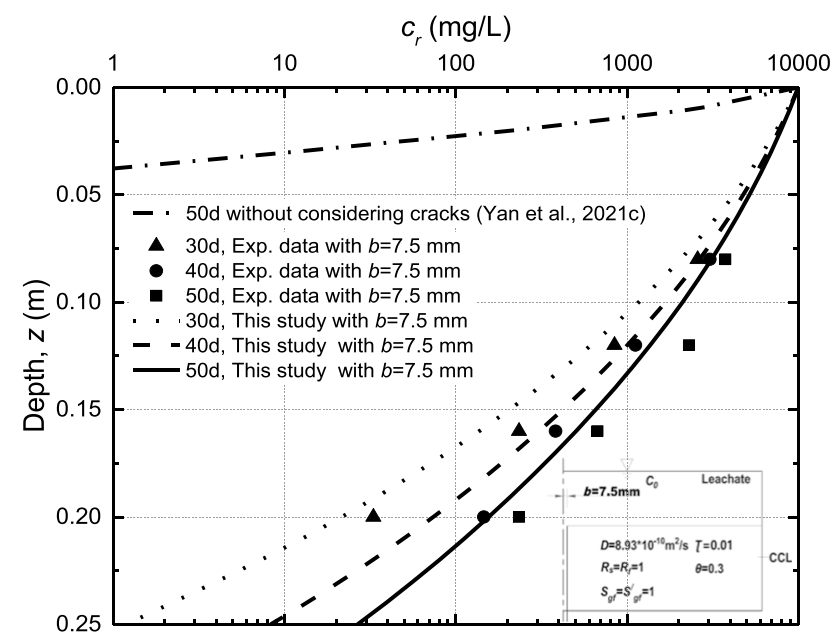

(a)

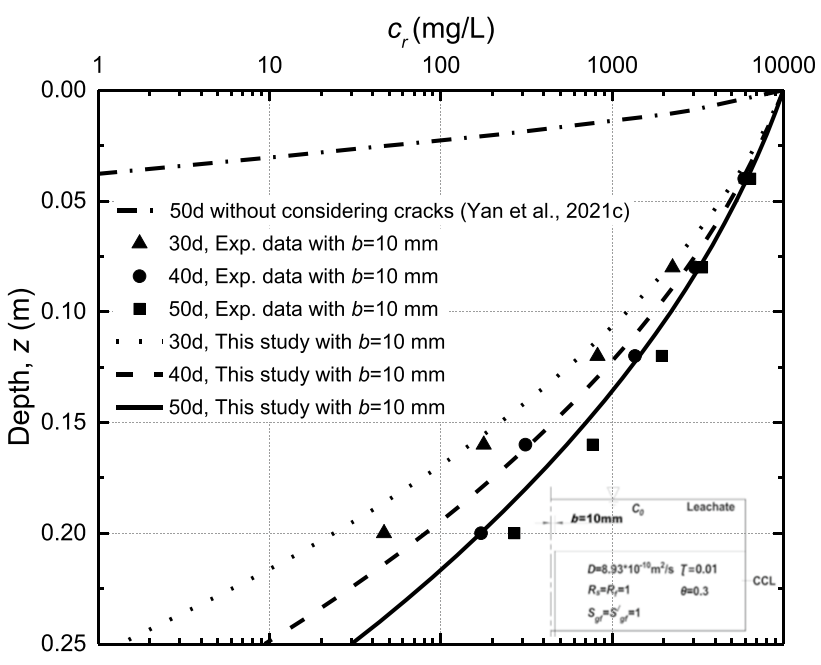

(b)

Fig. 2 Comparisons of the results from this study and experimental data obtained by Li et al. (2018)

Table 1 Values of $R^{2}$

\begin{tabular}{lll}
\hline Crack width & Time (day) & $\begin{array}{l}\text { Coefficient of } \\
\text { determination, } \\
R^{2}\end{array}$ \\
\hline$b=7.5 \mathrm{~mm}$ & 30 & 0.92 \\
& 40 & 0.96 \\
$b=10 \mathrm{~mm}$ & 50 & 0.83 \\
& 30 & 0.96 \\
& 40 & 0.97 \\
& 50 & 0.94 \\
\hline
\end{tabular}




\section{Effect of crack width}

The effect of crack on the steady-state concentration distribution of contaminants in the liner was investigated (see Fig. 3). The half-width of the crack (b) was $20 \mathrm{~mm}$. The results of the present solution are compared to the results obtained by Tang et al. (1981) and Xie et al. (2013). The model developed by Tang et al. (1981) mainly focused on the contaminant transport in a single soil layer with a single crack. The study carried out by Xie et al. (2013) investigated the performance of GMB/CCL composite liner without considering the effect of cracks. Figure 3 shows the steady-state organic contaminant concentration distribution along with the depth for different scenarios. In order to highlight the differences among the different scenarios, the significance test was conducted by using the Kruskal-Wallis approach (Bougara et al. 2020). It is initially assumed that there is no significant difference among the three scenarios with a significance level of $\alpha=0.05$. The original hypothesis does not hold when $P<\alpha$, which indicates a significant difference among the tests. A value of $P=1.06 \times 10^{-23}$ is obtained for the three scenarios (e.g., the present study, Tang et al. 1981, and Xie et al. 2013), which demonstrates a significant difference among the cases.

As can be seen in Fig. 3, the crack existing in CCL can significantly affect the distribution of contaminant concentration for single CCL and GMB/CCL composite liner. For example, the relative concentration at the bottom of $\mathrm{GMB} / \mathrm{CCL}$ composite liner for $b=20 \mathrm{~mm}$ is 3 times larger than that for the case without considering the crack. It is indicated that the GMB may provide a better diffusion barrier for the case without crack. Additionally, it can be seen that the relative concentration of contaminants at the surface of CCL is $1,0.72$, and 0.62 for the case with the single CCL, the composite GMB/CCL with and without crack, respectively. A smaller relative concentration profile is observed for the composite GMB/CCL

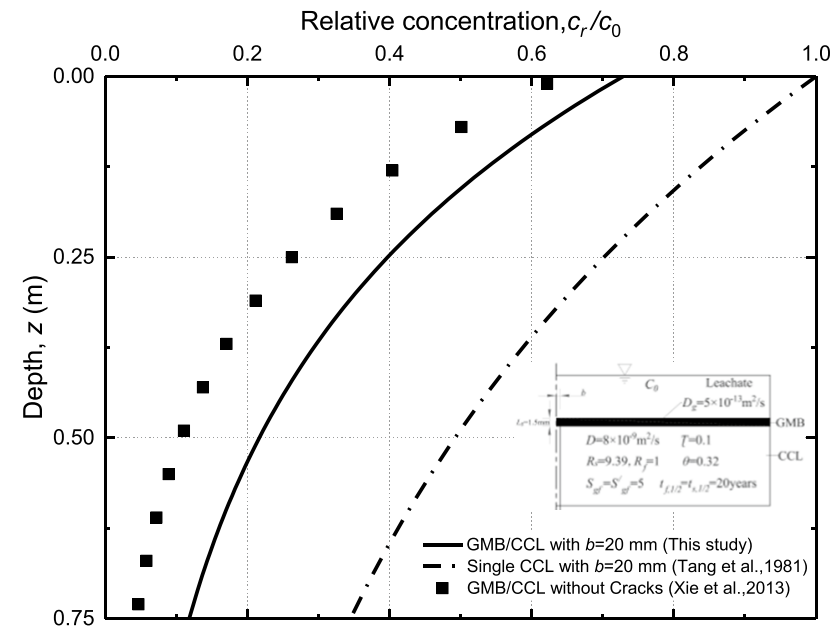

Fig. 3 Longitudinal concentration distribution of organic contaminants in cracks under different scenarios at a steady state

compared to the single CCL due to the partitioning process of organic contaminants in GMB. The above results also indicated that the GMB layer is an effective barrier for the reduction of contaminants in the landfill liner system. The existence of cracks in the composite liner increases the concentration profile of the contaminant as the cracks play as preferential paths for the diffusion of the contaminant in the cracking GMB/CCL (Eq. 21). It is noted that the diffusion coefficient of contaminants in the crack is much larger than that in CCL, which results in a faster contaminant migration through the liner system and reduce the performance of GMB as a diffusion barrier.

The Monte Carlo method was adopted in this section to carry out the statistical analysis of different parameters (e.g., retardation factor, degradation of contaminants, the porosity of CCL, and crack width) (Jacoboni and Reggiani 1983). The ranges of the half-width of the crack (b), the crack retardation factor $\left(R_{f}\right)$, the half-life of organic
Table 2 Values of the parameters of GMB and CCL used in parametric studies

\begin{tabular}{lll}
\hline & GMB & CCL \\
\hline Temperature (K) & 298.15 & \\
Atmospheric pressure (kPa) & 100 & \\
Thickness (m) & $1.5 \times 10^{-3}$ & 0.75 \\
Diffusion coefficient $\left(\mathrm{m}^{2} \mathrm{~s}^{-1}\right)$ & $5 \times 10^{-13 \mathrm{~d}, \mathrm{f}, \mathrm{g}}$ & $8 \times 10^{-10}-8 \times 10^{-11}$ \\
& & $20^{\mathrm{e}}$ \\
Half-life of organic contaminants (years) & - & $0.2-0.5^{\mathrm{b}}$ \\
Porosity (-) & $5^{\mathrm{d}, \mathrm{g}}$ & - \\
Partition coefficients (-) & - & $0-40^{\mathrm{a}, \mathrm{h}}$ \\
Crack width (mm) & - & $1-19^{\mathrm{c}, \mathrm{i}}$ \\
Crack retardation factor (-) & & \\
\hline
\end{tabular}

${ }^{\mathrm{a}}$ Basnett and Brungard (1992). ${ }^{\mathrm{b}}$ Musso et al. (2020). ${ }^{\mathrm{c}}$ Tang et al. (1981). ${ }^{\mathrm{d}}$ Touze-Foltz et al. (2012). ${ }^{\mathrm{e}} \mathrm{Wu}$

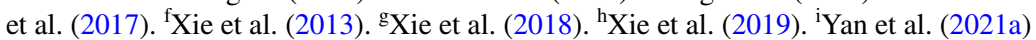


contaminants in cracks $\left(t_{f, 1 / 2}\right)$, and the porosity of CCL $(\theta)$ was assumed to be $0-25 \mathrm{~mm}$ (Basnett and Brungard 1992; Xie et al. 2019), 1-19 (Tang et al. 1981; Yan et al. 2021a), 10-90 years (Yan et al. 2021a), 0.2-0.44 (Musso et al. 2020), respectively. The average values of these parameters $b, R_{f}, t_{f, 1 / 2}, \theta$ are assumed to be $12.5 \mathrm{~mm}, 10$, 50 years, 0.32 , respectively, for the reference scenario. The above parameters are assumed to obey normal distribution. The $95 \%$ confidence interval of the reference scenario is constructed by a randomly generated 1000 dataset.

Figure 4 shows the effect of crack width on the breakthrough curve (Fig. 4a) and flux (Fig. 4b) of organic contaminants at the bottom of the crack $(z=0.75 \mathrm{~m})$. It can be seen that the crack width has a large effect on both the breakthrough time and bottom flux of organic contaminants. It should be noted that the value of relative concentration is shown by using logarithmic (log) scale as the value of relative concentration for the case with different crack widths varies a lot (e.g., $7 \times 10^{-4}$ for $b=0.5 \mathrm{~mm}$ and 0.2 for $b=12.5 \mathrm{~mm}$ ).

The breakthrough time is defined as the bottom concentration of contaminants reaching the maximum allowable concentration liner (Acar and Haider 1990; Zhan et al. 2017; Peng et al. 2020), which is assumed to be $10 \% c_{0}$ in this study. The breakthrough of the contaminant can be only found for the case with $b=12.5 \mathrm{~mm}$ (see Fig. 4a). It is indicated that the existence of cracks in CCL may damage the performance of the composite liner. Generally, the contaminant flux increases with the increase of crack width (Fig. 4b). For example, the steady-state fluxes for the case with $b=0.5 \mathrm{~mm}$ can be 90 times lower than that of $b=12.5 \mathrm{~mm}$. Additionally, increasing the crack width can shorten the time required to reach a steady state. The time to reach a steady state is 150 a and 60 a for $b=0.5 \mathrm{~mm}$ and $b=2.5 \mathrm{~mm}$, respectively. Additionally, the relative concentration and the bottom flux of $b=2.5 \mathrm{~mm}$ and $b=12.5 \mathrm{~mm}$ are almost within the $95 \%$ confidence interval of the reference scenario. The relative concentration and bottom flux dramatically decrease for a small width of crack (e.g., $b \leq 0.5 \mathrm{~mm}$ ). The above results indicated that considering the effects of the crack in CCL may help to design a more conservative, stable, and reliable landfill liner.

\section{Effects of degradation and adsorption}

Figure 5 shows the effects of half-life $\left(t_{f, 1 / 2}\right)$ and adsorption retardation factor $\left(R_{f}\right)$ on organic contaminant migration in the liner system. Generally, increasing the adsorption factor and degradation rate of contaminants can effectively slow

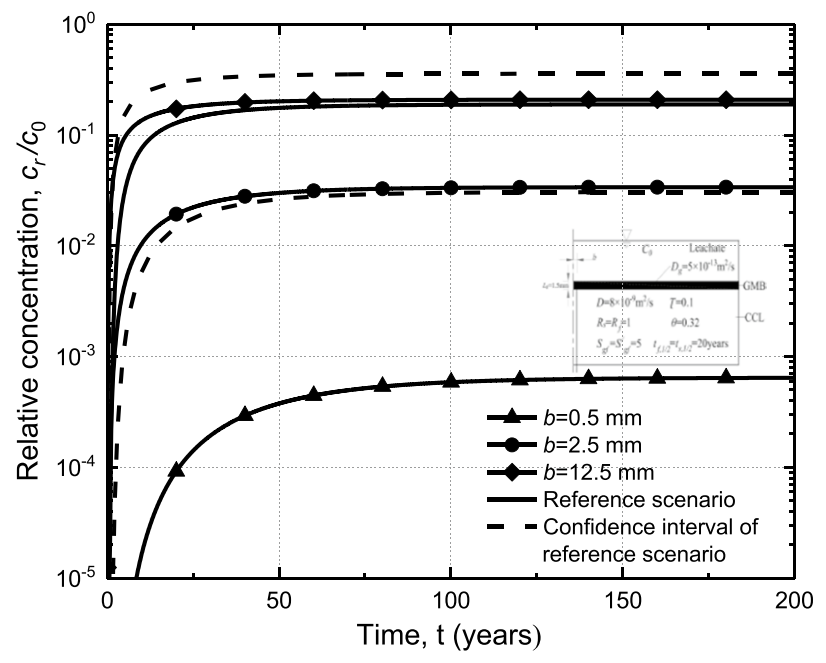

(a)

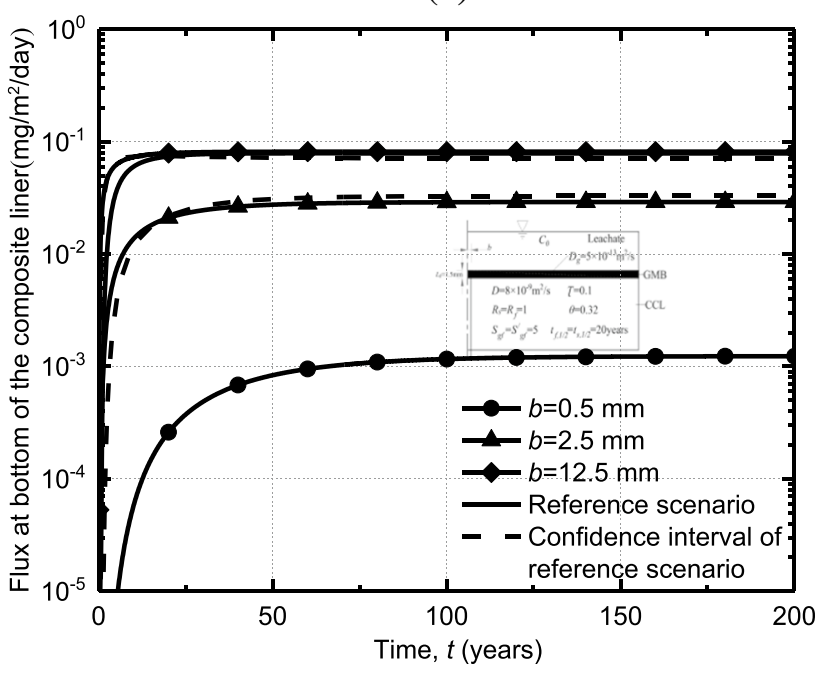

(b)

Fig. 4 Effect of different crack widths on organic pollutant breakthrough curves and fluxes

down the migration of contaminants in the liner system (Wood et al. 1990; Rowe et al. 2004; Xie et al. 2018). For example, increasing $R_{f}$ from 1 to 10 can lead to a reduction of steady-state bottom concentration of contaminants by a factor of 14 for $t_{f, 1 / 2}=1$ year. It is noted that the effect of adsorption is more significant than the degradation of contaminants on the breakthrough curve. For example, the steady-state concentration of contaminants for $R_{f}=1$ can be 11 times larger than that for $R_{f}=10$ with $t_{f, 1 / 2}=1$ year. At the same time, when $R_{f}=1$, the steady-state concentration of $t_{f, 1 / 2}=100$ years is only twice that of $t_{f, 1 / 2}=1$ year. Increasing the retardation factor can significantly slow down the transport of contaminants, which may indirectly create a longer period for the degradation of contaminants. 


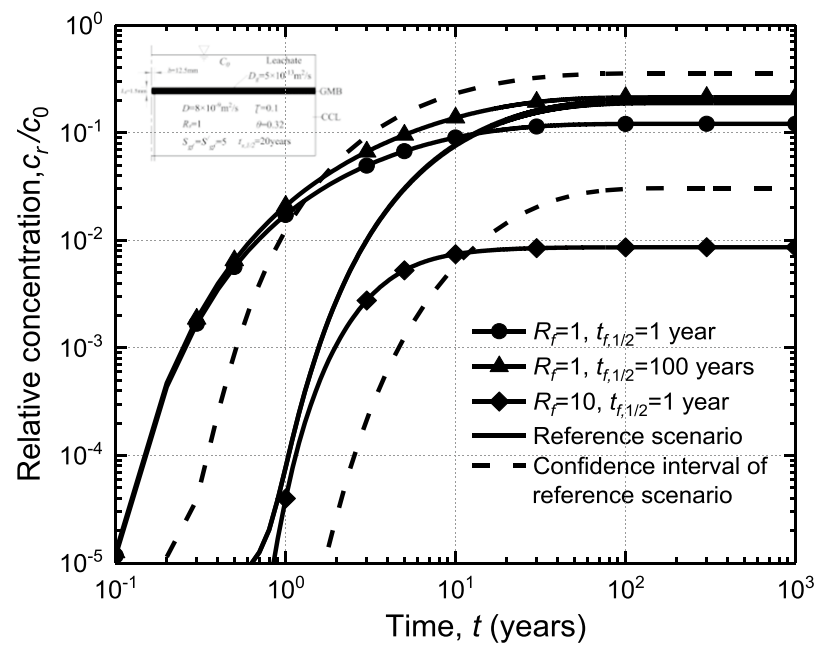

(a)

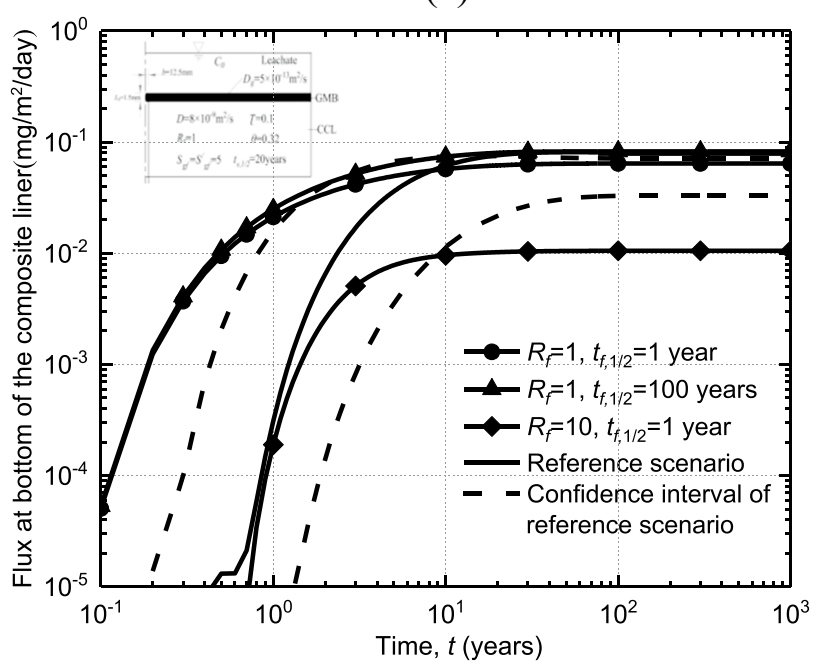

(b)

Fig. 5 Effect of retardation factor and half-life of organic contaminants on the breakthrough curves and fluxes in the liner

\section{Effects of porosity of CCL and crack width}

The four scenarios, including scenario $1(\theta=0.2, b=0.5)$, scenario $2(\theta=0.2, b=12.5)$, scenario $3(\theta=0.5, b=0.5)$, and scenario $4(\theta=0.5, b=12.5)$ are used to investigate the relative sensitivity of the bottom relative concentration to the porosity of CCL and crack width (Fig. 6). It can be seen that decreasing the porosity of the CCL (i.e., scenario 1 and scenario 3 ) will enhance the transport of contaminants within the crack in the composite liner. When $b=0.5 \mathrm{~mm}$, the maximum relative concentration for $\theta=0.2$ is about $3 \times 10^{-3}$, which is around 40 times higher than that for $\theta=0.5$. This may be due to the reduction of the porosity of the CCL, which results in less contaminant diffusing into CCL. In order to represent the distribution of contaminants in cracks more clearly, the concentration of pollutants along

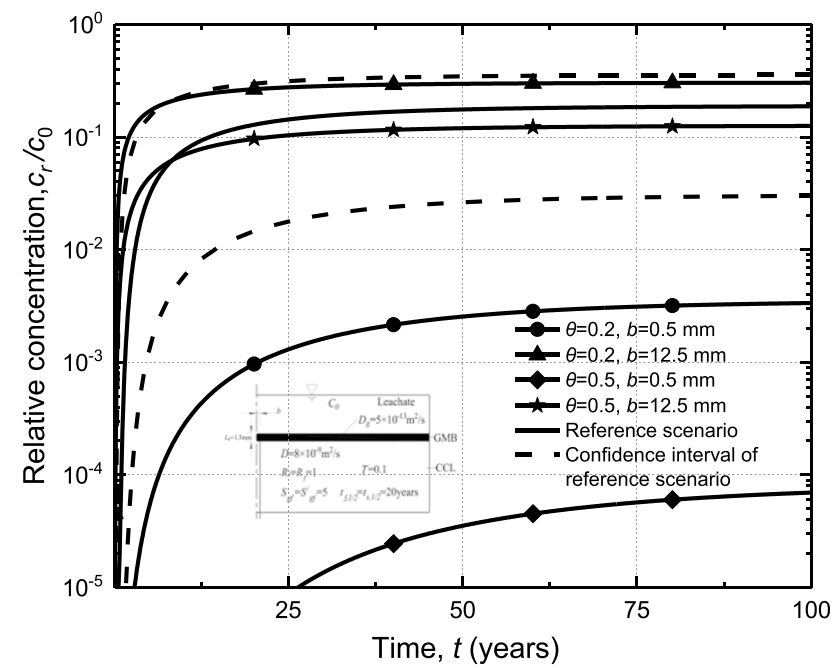

Fig. 6 Breakthrough curves of organic contaminants in cracks with different widths and porosity

cracks at $t=20$ years was calculated (as shown in Fig. 7). When $b=0.5 \mathrm{~mm}$, the relative concentrations of $\theta=0.2$ at $z=0.25 \mathrm{~m}, 0.5 \mathrm{~m}$, and $0.75 \mathrm{~m}$ were 10 times, 33 times, and more than 100 times of $\theta=0.5$, respectively. It can be seen that the relative bottom concentration of organic contaminants for the case with $b=12.5 \mathrm{~mm}$ is within the $95 \%$ confidence interval of the reference scenario. However, decreasing the half-width of the crack from $b=12.5 \mathrm{~mm}$ to $b=0.5 \mathrm{~mm}$ results in a significant reduction of contaminant concentration. The variations of crack width play a more important role in contaminant transport compared to the changes of porosity. Additionally, the effects of CCL porosity on the breakthrough curve are more significant for the case with a thinner crack. For example, the steady-state

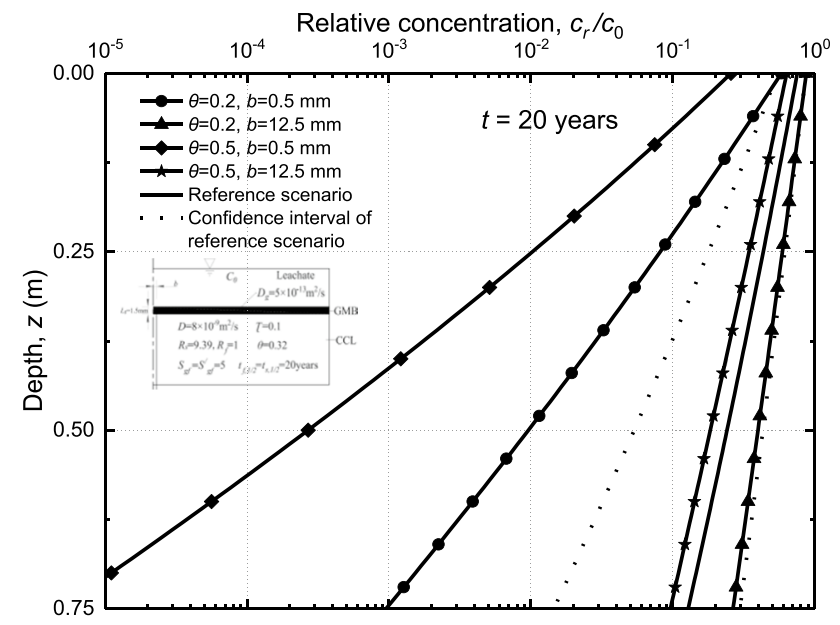

Fig. 7 Effect of widths and porosity in cracks on organic contaminant concentrations at $t=20$ years 
concentration of contaminants for the case with $b=12.5 \mathrm{~mm}$ can be 100 and 1800 times larger than that of the case with $b=0.5 \mathrm{~mm}$ for $\theta=0.2$, and $\theta=0.5$, respectively. It is indicated that the variations of CCL porosity are dominant for the cases with the small cracks (e.g., $b=0.5 \mathrm{~mm}$ ) as more amount of contaminant may diffusion into the matrix of CCL with a larger porosity. Interestingly, it can be found that there is a no-infiltration region for $\theta=0.2$. The phenomena can be explained by Fig. 7, which shows the contaminant concentration profile along with the depth at $t=20$ years for different crack widths and porosity. It can be seen that the maximum penetration depth of the contaminants is $0.7 \mathrm{~m}$ for $\theta=0.2$ and $b=0.5 \mathrm{~mm}$. This indicated that there is no contaminant reaching the bottom of the clay liner before 20 years and resulted in the no-infiltration region for the case.

\section{Limitations}

The proposed analytical model was not without limitations. It is assumed that the concentration of contaminants is constant and variation of concentration is not considered for simplifying the calculation. However, the landfill leachate varies greatly at different ages, and the concentration of contaminants in landfill leachate may vary significantly with time. The leakage of the composite liner was not considered; this could be important for the cases with high leachate head and poor construction quality of geomembrane. Also, the case of multiple cracks affecting each other is not considered; the occurrence of cracks is not isolated and requires further study.

This study focuses on investigating the transport of contaminants in a GMB/CCL under constant temperature and pressure. The influence of non-isothermal diffusion (e.g., thermal diffusion and temperature-dependent diffusion coefficient) and consolidation of the liner under pressure is therefore not considered; however, previous studies indicated that leachate has a wide temperature range (Rowe and Hoor 2009; Bouazza et al. 2017; Yan et al. 2021c), and the bottom liner often deforms under high vertical stress (Yu et al. 2018; Rowe and Yu 2019). All these factors may affect the transport of contaminants in composite liner and should be further studied. Additionally, the firstorder dynamic reaction model is adopted to investigate the degradation of organic contaminants in this study. It should be noted that the degradation of organic contaminants may show second-order or $n$th order degradation due to the influence of temperature and biological activities, although most organic contaminants can be described by the first-order biodegradation model (Báez et al. 2018; Shi et al. 2020). Other factors, such as heterogeneity and unsaturation of soil liner, may affect the performance of the liner system (Guyonnet et al. 2003; Yan et al. 2021c).

\section{Conclusions}

An analytical model for the diffusion of organic contaminants in the GMB/CCL composite liner with CCL cracks is presented. Laplace transformation and Laplace inversion using the Stehfest method were adopted to derive the analytical solution. The proposed analytical solution is validated by a set of experimental data. The model was used to study parametrically the effects of the crack width, the porosity of CCL, degradation, and adsorption on the overall transport of organic contaminants in the cracked composite liner system.

It was shown that the cracks in CCL may shorten the breakthrough time and increase the bottom flux of organic contaminants. For example, increasing the crack width from 1 to $25 \mathrm{~mm}$ can result in a faster breakthrough of contaminants by a factor of 280 . It is found that degradation of contaminants may play a more important role in the case with a larger retardation factor as increasing the retardation factor can slow down the transport of contaminants and indirectly create a longer period for the degradation of contaminants. Additionally, the reduction of porosity in CCL may enhance the transport of contaminants within the crack since the lateral diffusion of organic contaminants was greatly mitigated for the case with lower porosity.

Acknowledgements We appreciate the efforts of all the researchers whose articles were included in this study.

Author contribution Haijian Xie: conceptualization, funding acquisition, project administration, resources, supervision, writing-original draft, writing - review, and editing. Hao Ding: conceptualization, investigation, methodology, validation, visualization, writing —original draft, writing - review, and editing. Huaxiang Yan: conceptualization, resources, supervision, writing - original draft, writing — review, and editing. Dandi Yang: review and editing. Zhanghua Lou: review and editing. Zhanhong Qiu: review and editing. Yun Chen: review and editing.

Funding The financial support from the "Pioneer" and "Leading Goose" R\&D Program of Zhejiang (Grant No. 2022C03051), National Key R\&D Program of China (Grant Nos. 2018YFC1802303 and 2019YFC1806005), National Natural Science Foundation of China (Grant Nos. 51988101, 41977223 and 41931289), and Natural Science Foundation of Zhejiang province (Grant Nos. LR20E080002 and LCZ19E080001).

Availability of data and materials Data are available from the authors upon reasonable request.

\section{Declarations}

Ethics approval and consent to participate Not applicable.

Consent for publication Not applicable.

Competing interests The authors declare no competing interests. 
Open Access This article is licensed under a Creative Commons Attribution 4.0 International License, which permits use, sharing, adaptation, distribution and reproduction in any medium or format, as long as you give appropriate credit to the original author(s) and the source, provide a link to the Creative Commons licence, and indicate if changes were made. The images or other third party material in this article are included in the article's Creative Commons licence, unless indicated otherwise in a credit line to the material. If material is not included in the article's Creative Commons licence and your intended use is not permitted by statutory regulation or exceeds the permitted use, you will need to obtain permission directly from the copyright holder. To view a copy of this licence, visit http://creativecommons.org/licenses/by/4.0/.

\section{References}

Acar YB, Haider L (1990) Transport of low-concentration contaminants in saturated earthen barriers. J Geotech Eng 116(7):1031-1052

Báez ME, Espinoza J, Fuentes E (2018) Degradation kinetics of chlorpyrifos and diazinon in volcanic and non-volcanic soils: influence of cyclodextrins. Environ Sci Pollut Res 25(25):25020-25035

Basnett C, Brungard M (1992) Clay desiccation of a landfill composite lining system. Geotech Fabrics Rep 10(1)

Batt AL, Wathen JB, Lazorchak JM, Olsen AR, Kincaid TM (2017) Statistical survey of persistent organic pollutants: risk estimations to humans and wildlife through consumption of fish from US rivers. Environ Sci Technol 51(5):3021-3031

Bear J (2013) Dynamics of fluids in porous media. Courier Corporation

Birkhölzer J, Rubin H, Daniels H, Rouve G (1993) Contaminant advection and spreading in a fractured permeable formation: part 1. Parametric evaluation and analytical solution. J Hydrol 144(1-4):1-33

Bouazza A, Ali MA, Rowe RK, Gates WP, EI-Zein A (2017) Heat mitigation in geosynthetic composite liners exposed to elevated temperatures. Geotextiles Geomembranes 45(5):406-417

Bougara H, Hamed KB, Borgemeister C, Tischbein B, Kumar N (2020) Analyzing trend and variability of rainfall in the Tafna basin (Northwestern Algeria). Atmosphere 11(4):347

Chen Y, Xie H, Ke H, Chen R (2009) An analytical solution for onedimensional contaminant diffusion through multi-layered system and its applications. Environ Geol 58(5):1083-1094

Chen Y, Zhang J, Dong Y, Duan T, Zhou Y, Li W (2021) Phenolic compounds in water, suspended particulate matter and sediment from Weihe River in Northwest China. Water Sci Technol 83(8):2012-2024

Cvetkovic V, Frampton A (2012) Solute transport and retention in three-dimensional fracture networks. Water Resour Res 48(2)

DeCarlo KF, Shokri N (2014) Effects of substrate on cracking patterns and dynamics in desiccating clay layers. Water Resour Res 50(4):3039-3051

Dejam M (2019) Advective-diffusive-reactive solute transport due to non-Newtonian fluid flows in a fracture surrounded by a tight porous medium. Int J Heat Mass Transf 128:1307-1321

El-Zein A (2008) A general approach to the modelling of contaminant transport through composite landfill liners with intact or leaking geomembranes. Int J Numer Anal Meth Geomech 32(3):265-287

Espinosa-Reyes G, Costilla-Salazar R, Pérez-Vázquez FJ, GonzálezMille DJ, Flores-Ramírez R, Cuevas-Díaz MC, Medellin-Garibay SE, Ilizaliturri-Hernández CA (2019) DNA damage in earthworms by exposure of persistent organic pollutants in low basin of Coatzacoalcos River, Mexico. Sci Total Environ 651:1236-1242

Feng S, Peng M, Chen Z, Chen H (2019) Transient analytical solution for one-dimensional transport of organic contaminants through GM/GCL/SL composite liner. Sci Total Environ 650:479-492
Feng S, Zhu Z, Chen Z, Chen H (2020) Analytical model for multicomponent landfill gas migration through four-layer landfill biocover with capillary barrier. Int J Geomech 20(3):04020001

Foose GJ (2002) Transit-time design for diffusion through composite liners. J Geotech Geoenviron Eng 128(7):590-601

Guyonnet D, Gourry JC, Bertrand L, Amraoui N (2003) Heterogeneity detection in an experimental clay liner. Can Geotech J 40(1):149-160

Haddad AS, Hassanzadeh H, Abedi J (2012) Advective-diffusive mass transfer in fractured porous media with variable rock matrix block size. J Contam Hydrol 133:94-107

Hahn DW, Özisik MN (2012) Heat conduction. John Wiley \& Sons, New York

Hens B, Hens L (2018) Persistent threats by persistent pollutants: chemical nature, concerns and future policy regarding PCBs-what are we heading for? Toxics $6(1)$

Hirobe S, Oguni K (2017) Modeling and numerical investigations for hierarchical pattern formation in desiccation cracking. Physica D 359:29-38

Houseworth JE, Asahina D, Birkholzer JT (2013) An analytical model for solute transport through a water-saturated single fracture and permeable rock matrix. Water Resour Res 49(10):6317-6338

Inci G (2008) Numerical modeling of desiccation cracking in compacted soils. The 12th International Conference of International Association for Computer Methods and Advances in Geomechanics (IACMAG). pp 1-6

Jacoboni C, Reggiani L (1983) The Monte Carlo method for the solution of charge transport in semiconductors with applications to covalent materials. Rev Mod Phys 55(3):645

Kalbe U, Müller WW, Berger W, Eckaedt J (2002) Transport of organic contaminants within composite liner systems. Appl Clay Sci 21(1-2):67-76

Kjeldsen P, Barlaz MA, Rooker AP, Baun A, Ledin A, Christensen TH (2002) Present and long-term composition of MSW landfill leachate: a review. Crit Rev Environ Sci Technol 32(4):297-336

Koual M, Cano-Sancho G, Bats AS, Tomkiewicz C, Kaddouch-Amar Y, Douay-Hauser N, Ngo C, Bonsang H, Deloménie M, Lecuru F, Bizec BL, Marchand P, Botton J, Barouki R, Antignac J, Coumoul $X$ (2019) Associations between persistent organic pollutants and risk of breast cancer metastasis. Environ Int 132:105028

Lee ST, Chien MCH, Culham WE (1984) Vertical single-well pulse testing of a three-layer stratified reservoir. Society of Petroleum Engineers, SPE Annual technical conference and exhibition

Li L, Chen J, Huang Y, Dou Z (2016) Experimental investigation and numerical simulation of contaminant migration in the compacted clay containing artificial fractures. Environ Earth Sci 75(2):134

Li L, Wang J, Huang Y (2018) Parameters of contaminant transport of compacted clay liners with fractures. Chin J Geotech Eng 40(10):1836-1842

Masoner JR, Kolpin DW, Furlong ET, Cozzarelli IM, Gray JL, Schwab EA (2014) Contaminants of emerging concern in fresh leachate from landfills in the conterminous United States. Environ Sci Process Impacts 16(10):2335-2354

Musso G, Azizi A, Jommi C (2020) A microstructure-based elastoplastic model to describe the behaviour of a compacted clayey silt in isotropic and triaxial compression. Can Geotech J 57(7):1025-1043

NBSC (National Bureau of Statistics of China) (2019) China Statistical Yearbook. Beijing, China

Odling NE, Roden JE (1997) Contaminant transport in fractured rocks with significant matrix permeability, using natural fracture geometries. J Contam Hydrol 27(3-4):263-283

Öman CB, Junestedt C (2008) Chemical characterization of landfill leachates -400 parameters and compounds. Waste Manage 28(10):1876-1891 
Omidi GH, Thomas JC, Brown KW (1996) Effect of desiccation cracking on the hydraulic conductivity of a compacted clay liner. Water Air Soil Pollut 89(1):91-103

Pal DK, Dasog GS, Bhattacharyya T (2009) Pedogenetic processes in cracking clay soils (Vertisols) in tropical environments of India: a critique. J Indian Soc Soil Sci 57(4):422

Peng C, Feng S, Zheng Q, Ding X, Chen Z, Chen H (2020) A twodimensional analytical solution for organic contaminant diffusion through a composite geomembrane cut-off wall and an aquifer. Comput Geotech 119:103361

Peng Y, Fang W, Krauss M, Brack W, Wang Z, Li F, Zhang X (2018) Screening hundreds of emerging organic pollutants (EOPs) in surface water from the Yangtze River Delta (YRD): occurrence, distribution, ecological risk. Environ Pollut 241:484-493

Rayhani MHT, Yanful EK, Fakher A (2007) Desiccation-induced cracking and its effect on the hydraulic conductivity of clayey soils from Iran. Can Geotech J 44(3):276-283

Ritchie JT, Adams JE (1974) Field measurement of evaporation from soil shrinkage cracks. Soil Sci Soc Am J 38(1):131-134

Roubinet D, de Dreuzy JR, Tartakovsky DM (2012) Semi-analytical solutions for solute transport and exchange in fractured porous media. Water Resour Res 48(1)

Rowe RK, Quigley RM, Brachman RWI, Booker JR (2004) Barrier systems for waste disposal facilities. Spon Press

Rowe RK (2005) Long-term performance of contaminant barrier systems. Geotechnique 55(9):631-678

Rowe RK, Hoor A (2009) Predicted temperatures and service lives of secondary geomembrane landfill liners. Geosynth Int 16(2):71-82

Rowe RK, Abdelatty K (2013) Leakage and contaminant transport through a single hole in the geomembrane component of a composite liner. J Geotech Geoenviron Eng 139(3):357-366

Rowe RK, Yu Y (2019) Magnitude and significance of tensile strains in geomembrane landfill liners. Geotext Geomembr 47(3):439-458

Sampaio GR, Guizellini GM, da Silva SA, de Almeida AP, PinaffiLangley ACC, Rogero MM, de Camargo AC, Torres EAFS (2021) Polycyclic aromatic hydrocarbons in foods: biological effects, legislation, occurrence, analytical methods, and strategies to reduce their formation. Int J Mol Sci 22(11):6010

Sangam HP, Rowe RK (2001) Migration of dilute aqueous organic pollutants through HDPE geomembranes. Geotext Geomembr 19(6):329-357

Shackelford WM, Keith LH (1976) Frequency of organic compounds identified in water. Environmental Protection Agency, Office of Research and Development, Environmental Research Laboratory, Analytical Chemistry Branch

Shackelford CD (1990) Transit-time design of earthen barriers. Eng Geol 29(1):79-94

Shi Y, Yan F, Jia Q, Wang Q (2020) Norm index for predicting the rate constants of organic contaminants oxygenated with sulfate radical. Environ Sci Pollut Res 27(1):974-982

Sima J, Jiang M, Zhou C (2014) Numerical simulation of desiccation cracking in a thin clay layer using $3 \mathrm{D}$ discrete element modeling. Comput Geotech 56:168-180

Stehfest H (1970a) Algorithm 368: Numerical inversion of Laplace transforms [D5]. Commun ACM 13(1):47-49

Stehfest H (1970b) Remark on algorithm 368: Numerical inversion of Laplace transforms. Commun ACM 13(10):624

Tang AM, Cui Y, Barnel N (2008a) Thermo-mechanical behaviour of a compacted swelling clay. Géotechnique 58(1):45-54

Tang C, Shi B, Liu C, Zhao L, Wang B (2008b) Influencing factors of geometrical structure of surface shrinkage cracks in clayey soils. Eng Geol 101(3-4):204-217

Tang DH, Frind EO, Sudicky EA (1981) Contaminant transport in fractured porous media: analytical solution for a single fracture. Water Resour Res 17(3):555-564
Touze-Foltz N, Ahari M, Mendes M, Barral C, Gardoni M, Mazeas L (2012) Diffusion of phenolic compounds through an HDPE geomembrane. Geotech Eng J SEAGS \& AGSSEA 43(3):19-29

Trabelsi H, Jamei M, Zenzri H, Olivella S (2012) Crack patterns in clayey soils: experiments and modeling. Int J Numer Anal Meth Geomech 36(11):1410-1433

Wan Y, Xue Q, Liu L, Wang S (2018) Relationship between the shrinkage crack characteristics and the water content gradient of compacted clay liner in a landfill final cover. Soils Found 58(6):1435-1445

Wei X, Gao C, Liu K (2020) A review of cracking behavior and mechanism in clayey soils related to desiccation. Adv Civ Eng 9:1-12

Wood WW, Kraemer TF, Hearn PP (1990) Intragranular diffusion: an important mechanism influencing solute transport in clastic aquifers. Science 247(4950):1569-1572

Wu J, Yuan J, Ng CWW (2012) Theoretical and experimental study of initial cracking mechanism of an expansive soil due to moisturechange. J Central S Univ 19(5):1437-1446

Wu X, Shi J, He J (2017) Analytical solutions for diffusion of organic contaminant through composite liner considering degradation in leachate and soil liner. Int J Environ Pollut 61(2):166-185

Xie H, Lou Z, Chen Y, Jin A, Zhan TL, Tang X (2013) An analytical solution to organic contaminant diffusion through composite liners considering the effect of degradation. Geotext Geomembr 36:10-18

Xie H, Jiang Y, Zhang C, Feng S (2015a) An analytical model for volatile organic compound transport through a composite liner consisting of a geomembrane, a GCL, and a soil liner. Environ Sci Pollut Res 22(4):2824-2836

Xie H, Jiang Y, Zhang C, Feng S, Qiu Z (2015b) Steady-state analytical models for performance assessment of landfill composite liners. Environ Sci Pollut Res 22(16):12198-12214

Xie H, Yan H, Feng S, Wang Q, Chen P (2016) An analytical model for contaminant transport in landfill composite liners considering coupled effect of consolidation, diffusion, and degradation. Environ Sci Pollut Res 23(19):19362-19375

Xie H, Zhang C, Feng S, Wang Q (2018) Analytical model for degradable organic contaminant transport through a GMB/GCL/AL system. J Environ Eng 144(3):04018006

Xie H, Wang Q, Wu J, Chen Y (2019) Analytical model for methane migration through fractured unsaturated landfill cover soil. Eng Geol 255:69-79

Yan H, Wu J, Thomas HR, Ding H, Zhan L, Xie H (2021a) Analytical model for coupled consolidation and diffusion of organic contaminant transport in triple landfill liners. Geotext Geomembr 49(2):489-499

Yan H, Xie H, Wu J, Ding H, Qiu Z, Sun Z (2021b) Analytical model for transient coupled consolidation and contaminant transport in landfill liner system. Comput Geotech 138:104345

Yan H, Sedighi M, Ding H, Sun Z, Xie H (2021c) Analytical model for non-isothermal diffusion of contaminants in unsaturated composite liner. J Hydrol 603:126848

Yu C, Liu J, Ma J, Yu X (2018) Study on transport and transformation of contaminant through layered soil with large deformation. Environ Sci Pollut Res 25(13):12764-12779

Zhan L, Chen C, Wang Y, Chen Y (2017) Failure probability assessment and parameter sensitivity analysis of a contaminant's transit time through a compacted clay liner. Comput Geotech 86:230-242

Zhu Y, Zhan H, Jin M (2016) Analytical solutions of solute transport in a fracture-matrix system with different reaction rates for fracture and matrix. J Hydrol 539:447-456

Publisher's note Springer Nature remains neutral with regard to jurisdictional claims in published maps and institutional affiliations. 